\title{
THE STRUCTURE OF ACQUAINTANCE NETS AND RATES OF SOCIETAL DEVELOPMENT *
}

\author{
Manfred KOCHEN ** \\ University of Michigan
}

Selected steps in progress on the "small world problem" are reviewed, to show the difficulty of finding models that can produce the spectrum of clusters that is observed in contact nets rather than a single large cluster. Empirical work now in progress in the Philippines and in Hong Kong to correlate the structure of the acquaintance nets with rates of economic, political and societal development is presented and related to next steps in modelling. The relation of both empirical and theoretical findings to networking is brought out. as is the potential of computer conferencing for such network-supported applications as the provision of support in health maintenance.

\section{The small world problem}

On a Sunday in June 1984, on a lecture tour in China, I unexpectedly encountered the director of our Planning PhD Program, in which I have an appointment, in the very center of an island in West Lake in the tourist city of Hagzhou, which is three hours by train from Shanghai. On the train back to Shanghai, I met an American professor from Rutgers who was also lecturing in China, and with whom I shared a close colleague at Rutgers. These two were not the only instances of seemingly improbable contacts among a large number of possibilities during a few days. The counter-intuitively high chance of such contacts makes the social world seem small.

* The collaboration of Edric Ho and Kirk Cuthbert, both PhD students in the Sociotechnological Systems Area of the Urban, Technological and Environmental Planning (UTF.P) Program at the University of Michigan is gratefully acknowledged. The new empirical work was done by them. Partial support from UTEP, as well as from the National Science Foundation under grant IST 830-1505 is also gratefully acknowledged. I also thank Charles Barr and David West for helping in the preparation of the paper.

This paper was presented at the 1985 Sunbelt Social Networks conference in Palm Beach, Florida.

** Mental Health Research Institute, 205 Washtenaw Place, Ann Arbor, MI 48109-0010. U.S.A. 
The Chinese hosts at the four universities I visited all knew the person who arranged the visit. And that person was the chairman of a department that employed my partner in the lecture tour, who had come to the United States as a Fulbright Scholar and is conducting his research under my supervision on information systems to support matching processes. He formed many new Chinese acquantances during our lecture tour, and he is also forming many in the United States. Upon his return to China, all these acquaintances will play an important role in enabling him to contribute to the further development of China.

There may be a vast untapped potential in a suitably organized social acquaintance net for spurring development in novel ways. It may be of some value to pursue an analogy between acquaintance nets and a neural net, with neurons or neuronal groups corresponding to individuals or small groups such as families, and the acquaintance links corresponding to synaptic connections. A neural net, probably by virtuc of its network structure, can exhibit higher mental function. Analogously, an acquaintance net can exhibit higher societal fuctions, with self-development among them. The small world phenomenon of the remarkable encounters of people likely to be able to support one another, presumably because the social acquaintance net has certain structural properties, is important for two reasons. The first is purely scientific. It arouses our sense of wonder and challenges our ability to explain it. The second is utilitarian. Even if we cannot explain it, we can use it to steer and plan societal development.

In the remainder of this section I briefly sketch a series of attempts at constructing explanatory models and conclude by highlighting the theoretical challenge that still exists. In the next section, I discuss how the speed of societal development may be related to the structure of acquaintance nets. Then, some issues in the empirical study and some of our recent progress in these will be discussed; the issue of boundedness, for example, is viewed as one as the extent to which bounds can be estimated. This issue is central to the general problem of sampling a large, non-random network.

The first systematic study of acquaintance nets was started by Ithiel de Sola Pool and me in 1957, although there had been numerous anecdotal accounts of the phenomenon and studies of special aspects before then (it was not published until 20 years later; Pool and Kochen 1978). At first we noted that the simplest model, in which cach of, say 
100 million persons in a society has 1000 acquaintances, and if the events of a randomly chosen person belonging to the acquaintance circles of two given others are statistically independent, then the acquaintances of the acquaintances of any person number $1000 \times 1000$, and their acquaintances will exhaust the population. Thus, any person could connect with any other person through a chain of two intermediary acquaintances.

The average number of common acquaintances under the above conditions is approximately 0.01 with a variance of 0.01 . This implication of the independence assumption is far too small to be realistic. We replaced it by assuming that $M(k)$, the average number of acquaintances common to $k$ randomly chosen individuals is $a^{k-1} n$, where $n$ is the volume of a person's acquaintances; $0<a<1$, with $a=0.003$ for $n=1000$ and a population of $10^{8}$. Then $M(2)=3$, but $M(3)=0.009$, also too small to be realistic. A further refinement in our computation method led to values for $P(k)$, the probability of a chain with $k$ exactly intermediaries, of $0.00001,0.001,0.627$ and 0.234 for $k=0,1,2,3$ respectively. This is plausible, but the underlying model was not rich enough to account for the variability we knew existed and the other data we had.

We then introduced social strata into our models and found that the departure from the model without strata to be quite small. Viewing the entire societal acquaintance net as a connected graph, we noted that nuclei are bridged by longer chains quite well, so that the mean length of chains between randomly chosen pairs is affected only modestly by stratification. With or without strata, the modal number of intermediaries in the minimum chain between randomly chosen Americans should be around 2. For the whole world, probably only one more bridging individual may be needed.

In 1973, we explored an interesting but abstract and remotely relevant simulation model for the dynamics of acquaintance bond formation. It resembles models for the statistical mechanics of cooperative physical systems. An individual was treated as analogous to a particle located at each time at somc point in a social spacc, which was modeled as a square in the plane. An individual $A$ moves a unit distance from its position with a probability that changes so as to favor motion toward the center of a group of individuals each of whom $A$ has met up to that time. A meeting or contact is said to occur if there is an intersection of the paths that are taken by two individuals during one 
simulation cycle. With 225 individuals on a $15 \times 15$ square grid and probabilities changing by 0.2 , clustering is found after the tenth iteration. But by the 20 th iteration, all clusters coalesce into a single group, contrary to what would be realistic. We should have seen this to be an immediate consequence of the assumption that only attractive forces are at work. To prevent this analog of "gravitational collapse", it is necessary to introduce the equivalence of a repulsive force or "angular momentum". If, in place of randomly assigning at the start of simulation only positions to each individual, we assigned velocities (or momenta). introduced an upper limit to the number of contacts an individual can encounter per unit time, as well as a bound on the cumulative number of different acquaintances an individual can maintain, plus boundaries to regions in social space an individual is confined to, then we may get more realistic results. An analog to the mass of a particle might be resistance to an increase in the probability of change in position and velocity in response to the attraction of clusters to which that individual belongs. The closer individuals are to one another by virtue of having coalesced into a cluster the more frequently they contact one another; yet contacts with others also occur, though much more rarely. Pool and I had obtained empirical estimates of the number of others with which a randomly chosen has contacts with varying degrees of frequency, against which a simulation model is to be tested and to which its parameters should be fit. Clustering also ensures that the number of others with whom a randomly chosen individual in a cluster has exactly $k$ common acquaintances is quite high for small $k$; but there are also a few others outside the cluster for higher $k$. The more cliquishness or structure in a society, the longer the chains needed on the average to link a randomly chosen pair. The less the departure from a purely random process of interaction. in which any two persons have an equal change of meeting, the shorter will be the average minimum path per pair. Thus, if each person in a random net had 1000 acquaintances, there would be about $1000^{2}$ friends-of-friends if we disregard duplications, and a billion persons at the end of chains with two intermediaries and a trillion $\left(1000^{4}\right)$ with three. Finding an acquaintance in common-the small-world phenomenon-would still be a rare event. a chance of 10 out of 200 million. Two intermediaries would be all it would normally take to link two people, and only a small minority of pairs would be linked by one of those billion chains.

A final challenge to the construction of realistic models is the notion 
of "social space". It almost certainly requires many more than two dimensions and it is not Euclidean. This strains the capacities of even the most powerful computing resources available today. There may, however, be the possibility of a break from an unexpected source, the mathematics of cooperative systems or synergetics (Haken 1983), in the form of new mathematical formulations that enable us to cope with immensity and complexity with existing tools.

In 1984, two graduate students in the Planning PhD Program at the University of Michigan, Edric Ho and Kirk Cuthbert, who were going to Hong Kong and the Philippines respectively to work on their dissertations, became interested in the cross-cultural aspects of the small world problem. This presented a good opportunity to add to the empirical base to stimulate and guide the conceptual work needed to meet these intellectual challenges. At the same time, it made it possible to test important hypotheses about the relations between social structurc and socictal development.

\section{A model relating societal development to acquaintance nets}

Societal development includes economic development as one of its aspects. It also includes political and social development among other aspects. A measure of socioeconomic development was derived from a factor analysis of eight variables, (Haller 1982), such as manufacturing employment per worker in a micro-region. One factor accounts for 74.5 percent of the common variance and its eigenvalue is 5.956 , with the other seven all less than 1 .

Such factor analytically derived variables, if not easily interpretable as an important, readily imagined and intuitively meaningful concept (such as momentum or energy) are difficult to relate to other variables, such as societal structure. The rate of growth of spendable income is a better example, but it is not one of the eight variables used. This would include both spent income as this reflects standard of living and savings as well as the distribution or Gini indexes of these two. Per capita income is not a suitable indicator, but quality-of-life indexes, and data published by the World Bank, are appropriate.

A possible measure of political under-development is the extent to which there is resort to low-grade physical means, such as assassinations, tcrrorism, riots, etc., as opposed to higher-level mechanisms such 
as orderly voting, in managing leadership transitions. Another measure is the extent to which there is a fair and efficient propagation of influence on policy-making, resulting in policies that regulate power and security.

A measure of social development is the extent to which a development-conscious public realizes its potentials for well-being and settles for no less than they feel entitled to. These entitlement expectation levels are a measure of social development, too. The most direct evidence of social development may be social support, even though that may have decreased in societies, such as the U.S. and Sweden, that are economically and politically quite mature.

Changes in a society's economic development occur when there is an effect on mass markets, either within the society or outside of it as a result of changes in the organization or technology of enterprises. A market of 10,000 clients is quite respectable, and the reach of a network of acquaintances among businessmen and clients need not extend beyond this range. Changes in a society's political development, if it is a democracy, are affected by changes in the opinions of a larger public, generally 100,000 or so for a community of a million. Changes in social development are affected by changes in the lifestyles of millions. This requires a very far-reaching social acquaintance net.

Economic development is a process of coordinated specialization. It enables a community to perform productive functions it could otherwise not perform. It is a change toward a more complex structure that fits an "ecological niche" (Flammang 1978; Boulding 1978). To discover that niche requires ideas, imagination, courage and known-how. Of all the factors of production, know-how may be the scarcest. In Hong Kong, land is certainly scarce, but has not inhibited its development. Labor and capital are in principle as available in the Philippines as in Hong Kong or Taiwan and land alone cannot account for the difference. The quality of labor, enterprise and management may be different and that, in turn, affects the attractiveness to investors and hence the availability of capital.

Every production process begins with a plan. To produce and implement a plan requires good ideas, expertise, and understanding of the niche in the array of goods and services produced by society which the plan seeks to fill. These ideas and expertise - embodied know-how and experiences - are just as necessary to carry out a plan as capital, land, labor, and an available surplus of time, energy and the will to 
carry out plans. Meeting each of these prerequisites for performing new and appropriate productive functions is affected by the structure of the acquaintance network. The coming together of a venture capitalist, an entrepreneur and a manager capable of organizing the production process is much more likely if the three already know each other or at least have common acquaintances who bring them together. Organizing a project is not sufficient; it must also be appropriately staffed, and that too is largely determined by the contact net of the organizers. In brief, the more structured the acquaintance net, the shorter the chains likely to contribute to economic development and the greater the latter's rate, even if other chains are lengthened.

Economic development can be favored or inhibited by political and social factors. In The East Asia Edge, Hofheinz and Calder (1982) point to the political stability of the newly industrialized countries in East Asia as a major factor contributing to their attainments of the world's highest rates of economic development. A relatively lax regulatory climate often spurs new productive enterprises, even at the cost of inefficiency. In a society which is politically more developed, influence is propagated reasonable fairly and efficiently, resulting in stable and effective policies for regulating power and security, and their enforcement. Influence in such a society spreads in ways that allow the polity to adapt quickly to changing opportunities, newly discovered niches, varying constraints. Leadership transitions can take place in ways that mobilize widespread support by free and open information exchanges, by means that have at least the potential for raising the intellectual content and level of the debates above that of mere passions and self-serving power struggles to be settled by brute force.

Not all products of social stability are beneficial. Olson (1982) has hypothesized that stable conditions allow the proliferation of effective interest-group collectivities whose competitions cause gridlock; that is, society-wide choices and planning cannot be effectively undertaken because of this efficiency with which established acquaintance networks defeat change and adaptation that are interpreted as threats.

The essence of politics is the peddling of influence. This is largely the ability to reach a critical politician through the right channels. Again, in a highly structured acquaintance net, one in which politicians have many acquaintances and key people have many alternate and short channels or acquaintance chains through which to reach them, the propagation of influence is more likely to produce those properties of 
the polity that we have identified with more mature development. Data on regular us. irregular transfers of government personnel in the third edition of the World Handbook are likely to be useful here.

In an open society in which each individual has access to many channels of information that affect his levels of aspiration, the members are more likely to be aware of the gap between their potential and their status. They are not willing to settle for less than they feel entitled to. Thus. they are more likely to be upwardly mobile, to be achievenentoriented, to contribute to their society. Those aware of this gap and able to do so will more eagerly upgrade their education and skills. They will enrich their acquaintance networks as they are further educated and put their newly-acquired skills to work. (For example, they may form families by selecting marriage partners from new peer groups, setting the stage for a greater emphasis on education for the next generation.) These network-enriching processes contribute to political as well as economic development.

Conversely, economic, political and social developments improve the structure of the acquaintance net. Entrepreneurs, venture capitalists, organizers, job-seekers constantly seek out one another. Cocktail parties and conventions institutionalize the search for contacts. Each individual's circle of acquaintances is constantly expanded. Old contacts are renewed, useful bonds are reinforced, new ones added. The same holds for young men and women in search of mates, for politicians in search of supporters and constituents in search of representatives of their views. Thus, while an appropriately structured acquaintance network can be expected to contribute to societal development, increases in the latter can also add to the appropriateness of the acquaintance network's structure.

In Hong Kong and Singapore, we expect to find both high levels of societal development and a very structured, appropriate acquaintance net. In the Philippines and Malaysia, to the contrary, we expect to find relatively low levels and rates of societal development and a less structured acquaintance net.

\section{An empirical study}

The purposes of collecting and analyzing survey data from particular societies at various stages of development are twofold. First, we seek to 
discover correlations between societal development and acquaintance net structure, as hypothesized in the last section. Second, we want to add to the factual base to stimulate and support or refute explanatory models of the small world phenomenon, to discover basic principles by which social structures as reflected in acquaintance nets, develop, maintain themselves and function.

The first part of this section describes the design of the study. This is followed by a study of key methodological issues related to openness. Next, progress and partial results from the survey are reported and related to plans for further theoretical work.

Our hypotheses, reflecting some of Milgram's ideas, were that the patterns of contact in Asia differ from those in the U.S. in that there is much greater reliance on relatives and school friends in Asia. The shortest chain lengths in a randomly chosen pair decrease with levels and rates of economic development of an Asian country, and vary with target group within that country. The acquaintance network of former students enlarges over time and with progress in national economic development.

The core design employs both Milgram's passport technique and Killworth's reverse small world method. In the latter, a list of mythical target persons (together with town, occupation and race for each) is created by the experimenter, and a sample of chain-starters is presented with the list and with instructions to write down the name of one of their acquaintances to serve as the first link in a potential chain to each target.

With each choice, the respondent should also provide the type of the choice (friend, cousin, etc.), sex and the reason for the choice (location, occupation, ethnicity, other) (Killworth and Bernard 1978). Our fictitious target persons were associated with diverse socioeconomic backgrounds and included government officials, white-collar workers in private business, blue-collar workers, executives, and farmers.

Ideally, we plan to select a random sample of both chain-starters and chain-targets. For our pilot; the practical compromise between the ideal and the feasible, we took whoever was willing in both starter and target samples, mostly acquaintances of the student-experimenters.

We modified the procedure as follows. On the target list we gave the name, occupation/job title, mother language and location. As responses we requested the respondent to name the first link, his/her relation, and the reason for selection (job, language, location or other). 
This survey is being conducted by Kirk Cuthbert in the Philippines. It is planned to extend it to Malaysia and Singapore.

The reverse small-world technique makes it possible to estimate the distribution of acquaintanceship volume. Relatively little reliable data exists in which to base estimates about how many acquaintances a person has. Edrich Ho, our colleague in Hong Kong, included several items in his dissertation questionnaire that enabled us to draw some conclusions about the difference in peoples' own judgements about the number of their friends between Hong Kong and Southern China. We sketch here only the highlights of these findings; the details will be published separately.

Data from all of 95 respondents in Zhen-Zhen (a new city in the PRC adjoining Hong Kong) and (anton were compared with a compatible set of 95 responses drawn from a much larger group of Hong Kong respondents. The samples were matched on age groups (19 59), occupation (professional, executive, clerk, sales, service, factory workers. students) and levels of education. The main question was: "How many people do you estimate you could recognize by name and face, and vice versa" (in Chinese for most respondents). The percentages are given below:

$\begin{array}{lclllll} & <50 & 50-100 & 150-300 & 300-500 & 500-1000 & >1000 \\ \text { China } & 7.4 & 23.2 & 25.3 & 16.8 & 15.8 & 11.6 \\ \text { Hong Kong } & 19.1 & 36.2 & 18.1 & 13.8 & 8.5 & 4.3\end{array}$

That the Chinese give a higher estimate of how many people they know than the Hong Kong sample is significant at the 0.05 level.

In response to the question "Would you say that most people try to be helpful or are mostly looking out for themselves," 67.4 percent of the Chinese respondents said helpful compared with 42.6 percent of Hong Kongites. Similarly, 21.1 percent of the Chinese said "most people try to take advantage of you if they get the chance or ..." while 46.8 percent of the Hong Kongites said "... they would try to be fair." A large majority of Chinese said "most people can be trusted or ..." while the majority of the others said, "... you cannot be too careful in dealing with people." In response to "When you, yourself, hold a strong opinion, do you find yourself persuading others to share your views," 41.1 percent of the Chinese said often compared with 16.0 percent of the others. 
These four relations are not strongly correlated with perceived acquaintanceship volume. The Hong Kong sample suggests that the more people a person knows, the more they find others trustworthy and the more they would persuade others to share their views. This is contrary to a somewhat cynical remark attributed to Tolstoy: "The more I get to know people, the more I love my dog." (Dogs are conspicuously absent in China.) If the data on the categories of perceived acquaintanceship volume are collapsed or aggregated into two, the Chinese sample suggests, slightly, that the more people someone knows, the more he thinks that people look out for themselves and the more they would take advantage of him. For both samples, the number of people perceived to be known increases with age, though significantly for the Chinese sample. The China sample shows that belief in others being selfish, not trustworthy and taking advantage tends to go with a high perception of how many people they know. The Hong Kong sample suggests the opposite. Possibly the Chinese anticipate a more harmonious society than they have experienced so far.

In Hong Kong, the survey is being conducted by Edric Ho, but the University through which he made arrangements to do it preferred to use Milgram's small world method (Milgram 1967) rather than the reverse small world technique. Here the starter is given a folder or "passport" describing the target and instructed to pass it directly to the target only if he is a personal acquaintance (on a first-name basis), but if that is not the case, to send it to someone he does known who is also perceived as most likely to know the target.

This technique is afflicted by a higher attrition rate than the reverse small world method. The issue of reducing attrition also comes up in the use of chain letters to mobilize public opinion. In 1984, Y. Ito, a Japanese entomologist and peace activist, sent a letter to a set of people, asking each of them to forward it to ten others and to persuade them to forward it to ten others and adopt a position against the build-up of nuclear weapons and preparation for war. I received such a letter from one of my colleagues and forwarded one of my ten copies to Anatol Rapoport. A few wceks later, I rcceived a letter from A. Rapoport informing me that he had already received three such letters including the original from Japan. He wondered about the attrition, arguing that recipients would break the chain because of effort in thinking of further recipients, looking up their addresses, of making out an cnvelopc, stamping and mailing it. Therefore, he decided 
to make many copies of a letter containing these considerations and enclosing it in some of the letters he normally writes anyway. He also wondered how soon the chains close in on themselves. He suggested estimating the average life expectancy of a chain letter and its effect on the accumulation of support for the peace movement (see Appendix).

I'his seems like an interesting, novel technique for mobilizing political support for a position. It reflects the ordinary use of our correspondence networks. If we can measure whom such an enclosed letter reached, how it affected him or her and what action ensued, we can estimate the political effectiveness of such a device. It could also be used as a marketing device and may play a role in building social support. The substantive issue addressed in the Appendix is also relevant to this paper because the uncontrolled growth of nuclear weapons may be a counter-indicator to societal development.

The issue of attrition also occurs in snowball sampling, which has been used to sample a network. We used this method to determine some properties of the networks that link authors of scientific papers, referees and editors of the journals to which these papers are submitted for publication (Blaivas et al. 1982). We asked the editors of the main journals in six specialties to name persons they would most like to use as referees for the manuscripts they receive or whose manuscripts they would most like to receive. We then asked the persons so named to tell us whose papers they would most like to read or whom they would suggest as referees of their manuscripts. We repeated this for several rounds. The response rate at each phase was (I) $40 / 53$ or 75 percent (II) $104 / 350$ or 30 percent, (III) $150 / 771$ or 20 percent, and (IV) $269 / 440$ or 61 percent.

Another issue is the value of the last link added to a chain. As in the propagation of a rumor, some distortion is introduced and noise added at each remove from the origin. If we wish to sample chains from the network that is used to further societal. development by organizing and staffing enterprises, marshalling political support and building helpful social structures, we must be sure to observe chains that are not only stable but used and useful. They must have a sustained existence. Key actors in the development process must be aware of the chains in their entirety and of their value. Thus, we must sample from the population of stable, useful chains.

Many chains in that population will have the same persons in common - that is, they will intersect. It does not follow that two 
intersecting chains give a user starting with one of the chains two alternate paths. Different chains are useful for different purposes, and the same people belong to several different clusters and interest groups.

The distribution of chain lengths may be a characteristic of the acquaintance net's structures and reveal a great deal about the social structure of a society. It is quite likely to be a skew distribution, one that has a very long tail. For such distributions, the mean is a very poor estimate of any of its aspects; indeed, if the frequency of chain length $L$ varies as $1 / L$, then the mean cannot exist for an unbounded population. More generally, it may vary as $(1 / L)^{k}$ with smaller $k$ corresponding to a more skew distribution, one with a longer tail. In a highly and appropriately structured net, one that is well-organized, the distribution may be more skew. The most important chains are still very short, with one or two intermediaries mostly within the same cluster, but there are very many long chains that are rarely used.

Sampling from a network with a homogeneous structure, say one in which a small pattern is repeated, requires a sample large enough to contain the pattern. If the pattern is large, or more random, a larger sample must be taken. If little is known about homogeneity or the size or stochasticity of the pattern, rational sampling is very difficult. The issue of openness and boundedness arises only for sampling, for the total population is always finite, and therefore closed. A closed sampling method would involve selecting first a sample subpopulation, such as the population of a region or a particular community that is believed to be representative of the larger society, and either sampling or doing a population survey of that community. This is feasible, however, only if there is evidence that the total society's network is homogeneous and that there are moderately sized repeating patterns that are not too random.

\section{Social development and networking}

Networking includes the use of chains to provide social support as wcll as for the other functions of societal development discussed in the foregoing. Sidney Cobb has defined social support as information leading a person to believe that he is esteemed and valued and that he belongs to a network of communication and mutual obligation. More recently, House extended this definition to include "the flow between 
people of emotional concern, instrumental aid, information or appraisal". The level of a person's social support is the extent to which he can count on, is aware of and attends to regular access to sources of support when he needs it. Somehow, high levels of social support seem to protect organisms against stress. Indeed, a recently completed longterm epidemiological study confirms earlier findings of significantly higher death rates among people with lower levels of social support. House believes that the "prevalence of significant informal social relationships, social networks, and social supports has been declining over the last quarter century, while people are increasingly calling on those same dwindling informal sources of support for help in dealing with personal problems". (ISR Newsletter, University of Michigan, Aut. 1984, 5-6).

Perhaps creative innovations in the use of computer-communications technologies (e.g. on-line conferencing) combined with newer forms of managing the dynamics of two-way interactive matching processes can reverse this trend. Important work is being done at present in this direction by Gordon (1985) and Yuan (1984) and others. Showing how these sociotechnological systems can increase the number of support sources, the flow of emotional concern, and information and appraisal among people, has yet to be done. For both this purpose as well as for explaining the small world phenomenon, and for furthering societal development, many important conceptual challenges must be met at the same time.

Three kinds of issues are important in selecting strategies for research in this area. The first concerns the secrets of network structure; what are the most appropriate units of analysis? It is not necessarily the individual and his acquaintances anymore than the neuron is the most appropriate unit of analysis of nervous systems. What are methods for coping with immense but coupled ensembles? Immensity calls for statistical methods, but unlike the particles in a gas each of which is interchangeable with any other, the units in a social net are coupled and act together. A new kind of statistical conceptualization is called for. What, finally, are properties of such ensembles that are due to nonlinear relations and strong deviations from equilibrium? These, presumably, are societal analogs of higher mental functions, such as symbol-formation, self-reference, imagination.

The second class of issues concerns promising approaches to conceptualization. By analogy to "statistical mechanics", we call our approach 
"statistical socio-dynamics", though perhaps the word "structural" should replace "statistical". We have already mentioned near the end of Section 1 some of the features a new simulation model should have. The concept of a probabilistic "fractal" or self-similar structure seems worth exploring in the context of social net. We may find the same structure as we zoom in our view of a social network from that of a highly aggregated perspective to that of a most fine-grained view of a local region in the net. It is the regularities of a network structure that make it usable for people whose uncertainties about which chains to use when cannot be too great.

The third class of issues concerns promising research activities. In this area, it may be very fruitful to learn by doing, by using and observing the use of acquaintance nets in societal development. This implies the use and construction, if necessary, of sociotechnological systems such as computer conferencing to build social support. Information systems to support job matching, mate selcction, institutionbuilding are another example. On a note of exploratory statistical research, it is important to estimate the stochasticity, complexity and size of patterns in the acquaintance net, to what extent these patterns are repeating, and the homogeneity of the net.

We cannot yet specify the kind of structure for an acquaintance net that most facilitates effective and efficient networking for societal development. We do not even know how to describe this structure sufficiently to say whether it is homogeneous, whether there are repeating patterns, to what extent these patterns are probabilistically generated or specifiable, and how large and complex they are. Such issues require further clarification before empirical studies can produce sound inferences and valid, useful insights. Yet, the kinds of cross-cultural and cross-societal studies reported in this paper will provide guidance for the necessary creative conceptualization that is most needed. 


\title{
Appendix
}

\section{A novel chain letter}

\author{
Professor Yskie Ito \\ Laboratory of Applied Entomology \\ Nagova University \\ Furocho, Chikusa-ku \\ Nagoya, Japan \\ Dear Professor Ito:
}

Some time ago your chain letter reached me and I sent it on to ten friends. Since that time, I was contacted three more times. Many must have had that experience, since surely the chain closes in on itself. Probably few will make the effort to respond more than once or twice, if at all.

I am making several copies of this letter and will simply enclose one whenever I write to some one, a sort of modern version of Cato's "Delenda est Carthago", with which he ended every speech. This way of doing it costs practically no effort. I am sure it is the reluctance to make the effort involved in continuing a chain (thinking of to whom to send it on, mailing it, etc.) that breaks the chain. Sending the letter with other correspondence may be a way to keep it going. Who knows, with enough persistence of enough people something may come of it. Some one may even be inspired to do a bit of research on the life expectancy of chain letters with peace content and their effectiveness.

Now the message. Three points.

1. Nuclear weapons are represented as part of "defence". This is a deceptive usc of languagc. Nuclear weapons cannot defend anything or anybody. They can only destroy everything and everybody.

2. Nuclear weapons are represented as a "deterrent". If there were no nuclear weapons, a nuclear attack would be impossible. So it is absurd to say that nuclear weapons deter a nuclear attack. They do not deter "conventional" war either. Since 1945 this planet has not seen a single war-free year.

3. Nuclear weapons cannot be "balanced" either against themselves or against other weapons. Here or there some one is always ahead and some one behind in one weapons system or another. The side that is ahead never offers to scale its potential down to restore the balance. It is the side behind that always insists on catching up. "Balance of power" is an excuse to keep the arms race going.

None of the three rationales for nuclear weapons, "defence", "deterrence" or "balance of power" stands up under scrutiny. To take these shibboleths seriously is to think with one"s ears instead of with one's mind and heart. 


\section{References}

Blaivas, A., R. Brumbaugh, R. Crickman, and M. Kochen

1982 "Consensuality of Peer Nominations Among Scientists," Knowledge: Creation, Diffusion, Utilization 4(2) (December): 252-270.

Boulding, K.E.,

1978 Ecodynamics. Beverly Hills: Sage

Flammang, R.A.

1978 "Economic Growth and Economic Development", Economic Development and Cultural Change 28 (1): 47-61.

Gordon M., Rik Belew, M. Kochen and R. Lindsay

1985 "Information Construction Through Conferencing." To be presented at the National Online Meeting, NYC, April, 1985.

Haken, H.,

1983 Advanced Synergetics. Berlin: Springer-Verlag.

Haller, A.O.

1982 "A Socioeconomic Regionalization of Brazil", Geographical Review' 72 (4) (October): $450-464$.

Hofheinz, Roy and Kent Calder,

1982 The Eastasia Edge: New York: Basic Books

Killworth, P.D. and H.R. Bernard

1978 "The Reverse Small-World Experiment". Social Nerworks 1: 1959-1992.

Kochen, M.

1983 Information and Society. In Martha Williams (ed.), Annual Review of Information Science and Technology, Vol. 18. White Plains: Knowledge Industry Publications, Inc.

Kochen, M. and K.W. Deutsch

1980 Decentralization: Sketches Toward a Rationat Theory Cambridge, MA: OGH.

Milgram, S.,

1967 "The Small-World Problem", Psuchology Today 1: 61-67.

Olson, Mancur

1982 The Rise and Decline of Nations: Economic Growth, Stagflation, and Social Rigidities. New Haven: Yale University Press.

Pool, J. de Sola and M. Kochen

1978 "Contacts and Influence", Social Networks 1, 1-51.

Yuan, Yufei,

1984 Analysis and Design of Matching Support Systems. Dissertation, Computer and Information Systerns Area, Graduate School of Business Administration, University of Michigan, Ann Arbor, October. 